\title{
The first 1000 symptomatic pediatric SARS- CoV-2 infections in an integrated health care system: a prospective cohort study
}

Leigh M. Howard ${ }^{1}$, Kathryn Garguilo ${ }^{1}$, Jessica Gillon ${ }^{1}$, Kerry LeBlanc ${ }^{1}$, Adam C. Seegmiller², Jonathan E. Schmitz², Daniel W. Byrne ${ }^{3}$, Henry J. Domenico ${ }^{3}$, Ryan P. Moore ${ }^{3}$, Steven A. Webber ${ }^{1}$, Natasha B. Halasa ${ }^{1}$ and Ritu Banerjee ${ }^{1,4^{*}}$

\begin{abstract}
Background: The spectrum of illness and predictors of severity among children with SARS-CoV-2 infection are incompletely understood.

Methods: Active surveillance was performed for SARS-CoV-2 by polymerase chain reaction among symptomatic pediatric patients in a quaternary care academic hospital laboratory beginning March 12, 2020. We obtained sociodemographic and clinical data 5 (+/-3) and 30 days after diagnosis via phone follow-up and medical record review. Logistic regression was used to assess predictors of hospitalization.
\end{abstract}

Results: The first 1000 symptomatic pediatric patients were diagnosed in our institution between March 13, 2020 and September 28, 2020. Cough (52\%), headache (43\%), and sore throat (36\%) were the most common symptoms. Forty-one (4\%) were hospitalized; 8 required ICU admission, and 2 required mechanical ventilation (< $1 \%)$. One patient developed multisystem inflammatory syndrome in children; one death was possibly associated with SARS-CoV-2 infection. Symptom resolution occurred by follow-up day 5 in 398/892 (45\%) patients and by day 30 in 443/471 (94\%) patients. Pre-existing medical condition (OR 7.7; $95 \% \mathrm{Cl} 3.9-16.0$ ), dyspnea (OR 6.8; $95 \% \mathrm{Cl}$ 3.2-14.1), Black race or Hispanic ethnicity (OR 2.7; $95 \% \mathrm{Cl} 1.3-5.5$ ), and vomiting (OR 5.4; $95 \% \mathrm{Cl}$ 1.2-20.6) were the strongest predictors of hospitalization. The model displayed excellent discriminative ability (AUC $=0.82,95 \% \mathrm{Cl}$ $0.76-0.88$, Brier score $=0.03$ ).

Conclusions: In 1000 pediatric patients with systematic follow-up, most SARS-CoV-2 infections were mild, brief, and rarely required hospitalization. Pediatric predictors of hospitalization included comorbid conditions, Black race, Hispanic ethnicity, dyspnea and vomiting and were distinct from those reported among adults.

\section{Background}

Clinical features and outcomes associated with SARSCoV-2 infection may differ by age [1-5]. The spectrum of illness associated with SARS-CoV-2 infection in children is broad, including asymptomatic viral detection, and

\footnotetext{
* Correspondence: ritu.banerjee@vumc.org

'Department of Pediatrics, Vanderbilt University Medical Center, Nashville, TN, USA

${ }^{4}$ Medical Center North, 116121 st Avenue South, Nashville, Tennessee, USA Full list of author information is available at the end of the article
}

features of coronavirus disease 2019 (COVID-19), typically characterized by respiratory symptoms, fever, and sometimes diarrhea, headache, and anosmia $[3,6,7]$. The severity of illness has been reported to range from mild, transient symptoms to illness requiring hospitalization, intensive respiratory support, and even rarely death in children. There are increasing reports of a severe inflammatory syndrome occurring in the weeks after SARS-CoV-2 infection or exposure in children $[8,9]$, now

(c) The Author(s). 2021 Open Access This article is licensed under a Creative Commons Attribution 4.0 International License, which permits use, sharing, adaptation, distribution and reproduction in any medium or format, as long as you give appropriate credit to the original author(s) and the source, provide a link to the Creative Commons licence, and indicate if changes were made. The images or other third party material in this article are included in the article's Creative Commons licence, unless indicated otherwise in a credit line to the material. If material is not included in the article's Creative Commons licence and your intended use is not permitted by statutory regulation or exceeds the permitted use, you will need to obtain permission directly from the copyright holder. To view a copy of this licence, visit http://creativecommons.org/licenses/by/4.0/ The Creative Commons Public Domain Dedication waiver (http://creativecommons.org/publicdomain/zero/1.0/) applies to the data made available in this article, unless otherwise stated in a credit line to the data. 
known as multisystem inflammatory syndrome in children (MIS-C) [9-14]. However, current understanding of the full spectrum of manifestations of SARS-CoV-2 infection in children is very limited because most existing reports are derived from cross-sectional assessments of children with more severe illnesses, such as hospitalized children $[3,15-17]$. Less is known regarding the symptoms, illness duration, and predictors of severe illness among ambulatory children diagnosed in the community with SARSCoV-2 infection. Our objectives were to report the sociodemographic and clinical characteristics, including duration of symptoms, and clinical outcomes of children and adolescents diagnosed with SARS-CoV-2 infection in a large, integrated health network affiliated with an urban academic medical center in the southern United States (U.S.) and to identify predictors of hospitalization in these children.

\section{Methods}

\section{Study design and population}

Active laboratory surveillance was performed for all symptomatic children and adolescents with a positive SARS-CoV-2 test by polymerase chain reaction (PCR) in the clinical laboratory of a large quaternary care academic medical center in the southeastern U.S. The pediatric network of care of this medical center includes a large acute care pediatric hospital with 343beds, with over 16,000 inpatient discharges, 47,000 emergency department (ED) encounters, and 360,000 ambulatory clinic encounters each year. SARS-CoV-2 testing was offered in the inpatient, ED, and ambulatory settings, which includes a primary care network, 9 urgent care clinics that see pediatric patients, 6 pediatric-only urgent care clinics, 2 dedicated oncampus SARS-CoV-2 testing sites, and 14 urgent care clinics located within private retail pharmacies. This network serves a diverse patient population derived from across urban, suburban, and rural Tennessee, southern Kentucky, and northern Alabama. The study was reviewed and approved by the Institutional Review Board.

\section{SARS-CoV-2 testing}

Nucleic acid amplification testing for SARS-CoV-2 was performed with a variety of methodologies with Emergency Use Authorization by the US Food and Drug Administration (with multiple platform-use dictated by supply limitations). These platforms included a modified Centers for Disease Control and Prevention (CDC) qRTPCR assay, the Roche 6800, the Hologic Panther, the GenMark Eplex, the Diasorin Liaison, the Biofire FilmArray SARS-CoV-2 monoplex, the Cepheid GeneXpert, and the Abbott IDNOW. The CDC assay employed the N1 and N2 primer/probe sets for SARS-CoV-2 with amplification/detection on an Applied Biosystems QuantStudio 7 Flex. Specimens were nasopharyngeal or nasal swabs in viral transport media.

\section{Indications and locations for testing}

SARS-CoV-2 PCR testing became available in our institution on March 12, 2020. Given limited testing capacity, initial testing criteria were restricted to symptomatic individuals with new fever and respiratory symptoms or those with contact with a SARS-CoV-2 infected individual. Routine screening of asymptomatic individuals prior to hospital admissions, chemotherapy initiation, stem cell or organ transplant, or procedures requiring anesthesia began on May 4, 2020. If asymptomatic individuals were identified as subsequently developing symptoms, they entered our symptomatic cohort.

\section{Study follow-up}

For symptomatic patients, our team performed followup by phone to obtain baseline sociodemographic characteristics and ascertain data on exposures, comorbidities, clinical symptoms, and illness status. The phone followups were performed by a clinical nurse using a pre-specified list of questions and symptom check list. Early follow-up (day $5+/-3$ after laboratory diagnosis) was conducted for all patients, but later follow-up (30 days after diagnosis) was limited to a subset of patients due to insufficient staff in the face of rapidly rising cases at the end of the study period. We also reviewed electronic medical records (EMR), when available, to collect additional clinical and demographic information.

\section{Statistical analysis}

We modeled the association of several potential risk factors of interest on hospital admission using multivariable logistic regression. These factors included sociodemographic variables such as age, gender, racial, and ethnic backgrounds, and clinical factors including weight, body mass index (BMI), and the clinical symptoms known before admission (presence of shortness of breath, vomiting, fever), and pre-existing conditions. With only 41 hospitalizations, we limited the model to 4 predictors to avoid overfitting. The predictive accuracy of the final model was evaluated using the c-statistic, Brier score, and calibration curve. Bootstrap model validation was used to test for overfitting. Daily and 7-day moving average test positivity frequencies were calculated and stratified by asymptomatic and symptomatic status. Statistical analyses were conducted using STATA/SE 14.2 (StataCorp LP, College Station, TX) and R (version 3.5.0, rproject.org). 


\section{Results}

The first 1000 symptomatic pediatric patients identified in our healthcare network were diagnosed between March 13 and September 28, 2020 and their characteristics are summarized in Table 1 and Supplementary Fig. 1. Notably, $65 \%$ had a known close contact with SARS$\mathrm{CoV}-2$ infection. Approximately $18 \%$ of patients had at least one comorbidity. 801 (80\%) positive tests were collected in outpatient settings, 197 (20\%) in the ED, and 2 $(<1 \%)$ during hospital admission. The median duration of symptoms prior to SARS-CoV-2 testing was 2 days (IQR $1-3$ days, $n=754$ ).

\section{Clinical features of illness}

Overall, the most common symptoms associated with SARS-CoV-2 infection were cough (52\%), headache $(43 \%)$, sore throat $(36 \%)$, and fever $>100.4{ }^{\circ} \mathrm{F}$ (34\%; Fig. 1, Supplementary Table 1). Symptom type and frequency varied according to age group, although some patient-reported symptoms, such as anosmia or headache, may have been more difficult to identify in younger children. Fever and rash were reported in a significantly higher proportion of younger children than older children and adolescents, while sore throat and myalgia were more frequent in the older age groups.

We classified symptoms as respiratory (cough, rhinorrhea, sore throat, shortness of breath), gastrointestinal (GI; nausea/vomiting, diarrhea, abdominal pain), or general (headache, myalgia, anosmia, fatigue, chills, rash). Overall, three-quarters (75\%) of patients exhibited at least one respiratory symptom, $66 \%$ exhibited a general symptom, and $25 \%$ had at least one GI symptom. Twenty-three (2\%) patients had fever alone without other symptoms, which occurred in a similar distribution across age groups (data not shown).

Of 744 patients with at least one respiratory symptom, 499 (67\%) also exhibited at least one general symptom and 193 (26\%) exhibited at least one GI symptom. General symptoms occurred without respiratory or GI symptoms in 121 (12\%) patients. Only 18 patients (2\%) had a GI symptom without a respiratory or general symptom present; 13/18 (72\%) of these patients' GI symptoms were accompanied by documented or subjective fever.

\section{Hospitalizations}

Forty-one $(4 \%)$ patients were hospitalized for possible or probable COVID-19 shortly after diagnosis of SARSCoV-2 infection (Supplementary Table 2). Twenty-nine (71\%) of 41 hospitalized patients reported white race, while $24 \%$ reported Black race, and 15 (37\%) reported Hispanic ethnicity (Table 2). Twenty-seven (66\%) hospitalized patients had at least one comorbidity. Eight patients $(<1 \%)$ were admitted to the intensive care unit and two patients $(<1 \%)$ required mechanical ventilation. One patient in our cohort later developed MIS-C. There was one death that was possibly related to SARS-CoV-2.

\section{Symptom duration}

Of 1000 patients, $892(89 \%)$ were reached for at least one early follow-up phone call $(5+/-3$ days after diagnosis). The median time of the early follow-up call was 2 days (IQR 2-3) after COVID-19 diagnosis. Complete symptom resolution occurred by the time of the early follow-up phone call in 398/892 (45\%) patients. The median age was greater among patients with ongoing symptoms vs. those with symptom resolution at the time of the early follow-up (14.8 years, IQR 7.4-17.4 vs. 12.4 years, IQR 6.0-16.6; Wilcoxon ranksum $p=0.001$ ).

Symptom resolution occurred by day 30 in $443 / 471$ (94\%) patients who could be reached for follow-up. Among 28 patients with ongoing symptoms at day 30 , the median age was 13.3 years (IQR 3.9-16.8), and the most commonly reported ongoing symptoms were fatigue (6 patients), cough (5 patients), fever, and reduced sense of smell (4 patients each). No child was diagnosed with recurrent or "long" SARS-CoV-2 infection during the study period.

\section{Risk factors associated with COVID-19 hospitalization}

We developed a logistic regression model to assess risk of hospitalization associated with COVID-19 (Fig. 2, Supplementary Table 3). The presence of at least one pre-existing medical condition (OR 7.7; $95 \%$ CI 3.9 to 16.0), shortness of breath (OR 6.8; $95 \%$ CI 3.2 to 14.1), Black race or Hispanic ethnicity (OR 2.7; $95 \%$ CI 1.3 to 5.5), and vomiting (OR 5.4; $95 \%$ CI 1.2 to 20.6) were the strongest predictors of hospitalization (Fig. 2). A tree diagram reporting the relative contributions of each identified predictor is presented in Supplementary Fig. 2. Within pre-existing conditions, immunologic, neurologic, and renal conditions were the strongest predictors of hospitalization (Supplementary Fig. 3). Body mass index (BMI) and weight were not significantly associated with hospitalization (Supplementary Tables 3, Supplementary Fig. 4). A predictive model incorporating these variables had an AUC of 0.82 (95\% CI 0.76 to 0.88 ) and Brier score of 0.03 . The bootstrap model calibration using 40 replications showed minimal optimism in our estimates of model R-squared ( 0.28 apparent, 0.27 bias corrected), calibration intercept (0.0 apparent, -0.05 bias corrected), calibration slope (1.0 apparent, 0.98 bias corrected), and Brier score (0.03 apparent, 0.03 bias corrected) (Supplementary Fig. 5).

\section{Discussion}

In this large prospective cohort study of the first 1000 children with SARS-CoV-2 infection in our health 
Table 1 Sociodemographic and clinical features of symptomatic SARS-CoV-2 positive children and adolescents ${ }^{\mathrm{a}}$ diagnosed between $3 / 12 / 2020$ and $9 / 28 / 2020^{\mathrm{b}}$ ( $n=1000$ unless otherwise specified)

\begin{tabular}{|c|c|}
\hline Characteristic or clinical variable & No. (\%) \\
\hline Age (y), median, IQR & $14.0(7.2-17.3)$ \\
\hline Range & $0.04-22.8$ \\
\hline \multicolumn{2}{|l|}{ Age groups } \\
\hline$<1$ year & $87(9)$ \\
\hline $1-4$ years & $99(10)$ \\
\hline $5-9$ years & $140(14)$ \\
\hline 10-14 years & $230(23)$ \\
\hline$\geq 15$ years & $444(44)$ \\
\hline Gender, female & $523(52.3)$ \\
\hline \multicolumn{2}{|l|}{ Race $^{c}$} \\
\hline White & $789(78.9)$ \\
\hline Black & $129(12.9)$ \\
\hline Asian & $45(4.5)$ \\
\hline Multiracial & $72(7.2)$ \\
\hline Other or Unknown & $19(1.9)$ \\
\hline Hispanic ethnicity & $203(20.3)$ \\
\hline \multicolumn{2}{|l|}{ Testing location } \\
\hline Outpatient clinic or testing site & $801(80.1)$ \\
\hline Emergency department & $197(19.7)$ \\
\hline Hospital admission & $2(0.2)$ \\
\hline \multicolumn{2}{|l|}{ Method of data collection } \\
\hline Patient interview & $237(23.7 \%)$ \\
\hline Medical record review & $839(83.9 \%)$ \\
\hline \multicolumn{2}{|l|}{ SARS-CoV-2 exposure } \\
\hline Known household contact with COVID-19 & $409(40.9)$ \\
\hline Known community contact with COVID-19 & $241(24.1)$ \\
\hline Days to return test results (mean $\pm \mathrm{SD}$ ) & $1.1 \pm 1.3$ \\
\hline Median (range) & $1.0(0-17)$ \\
\hline Any comorbidity & $177(17.7)$ \\
\hline Chronic lung disease & $77(7.7)$ \\
\hline Neurologic condition & $33(3.3)$ \\
\hline Cardiovascular disease & $27(2.7)$ \\
\hline Diabetes mellitus & $10(1.0)$ \\
\hline Immunocompromising condition & $9(0.9)$ \\
\hline Chronic renal disease & $8(0.8)$ \\
\hline Other chronic condition & $65(6.5)$ \\
\hline Body mass index, median (IQR), $n=572$ & $20.3(17.1-23.8)$ \\
\hline Underweight (BMI < 18.5) & $165(28.8)$ \\
\hline Normal weight (BMI 18.5-24.9) & $280(49.0)$ \\
\hline Overweight (BMI 25-29.9) & $75(13.1)$ \\
\hline Obese (BMI $\geq 30)$ & $52(9.1)$ \\
\hline Symptom resolution at early follow-up $(n=892)$ & $398(44.6)$ \\
\hline
\end{tabular}

Table 1 Sociodemographic and clinical features of symptomatic SARS-CoV-2 positive children and adolescents ${ }^{a}$ diagnosed between $3 / 12 / 2020$ and $9 / 28 / 2020^{\mathrm{b}}$ ( $n=1000$ unless otherwise specified) (Continued)

\begin{tabular}{ll}
\hline Characteristic or clinical variable & No. (\%) \\
\hline Symptom resolution at later follow-up $(n=471)$ & $443(94.0)$ \\
Outcomes & \\
Hospitalization & \\
Remained outpatient & $959(95.9)$ \\
Admitted to hospital & $41(4.1)$ \\
ICU admission & $8(0.8)$ \\
Mechanical ventilation & $2(0.2)$ \\
Prescribed remdesivir & $9(0.9)$ \\
Death ${ }^{4}$ & $1(0.1)$ \\
Clinical symptoms & \\
Headache & $424(42.4)$ \\
Sore throat & $361(36.1)$ \\
Fever $>100.4 \mathrm{~F}$ (38.0 C) & $337(33.7)$ \\
Nausea or vomiting & $147(14.7)$ \\
Shortness of breath (dyspnea) & $98(9.8)$ \\
Abdominal pain & $82(8.2)$ \\
Vomiting & $16(1.6)$ \\
Hypoxia & $12(1.2)$ \\
\hline
\end{tabular}

${ }^{a}$ Cohort includes 995 individuals $<=18$ years of age and 5 individuals 19 and older who received long-term primary and subspecialty care in the pediatric facility (age range 19-22)

${ }^{\mathrm{b}}$ Includes 1 infant who developed symptoms and positive SARS-CoV-2 test at 5 weeks of age after being born to mother who was SARS-CoV-2 positive at time of delivery

cTotal $n>1000$ as several subjects reported association with more than one race category

${ }^{d}$ Cause of death not definitively associated with SARS-CoV-2 infection in patient with multiple comorbidities

system, we conducted intensive phone followup and were able to characterize spectrum and duration of symptoms as well as identify novel predictors of hospitalization in the minority of children who required inpatient care. We found that most children with SARSCoV-2 had good outcomes, remained outpatients, and nearly half had complete symptom resolution within 2 days of diagnosis. Our finding that pediatric illnesses were generally brief and mild, with only a small minority requiring hospital admission, intensive care, or mechanical ventilation are consistent with prior reports that children with SARS-CoV-2 infection experience less severe clinical outcomes than adults $[1,3,6,7,16,17]$.

The clinical features of illness in our cohort were similar to other pediatric studies from the U.S. and U.K, in which fever, cough, or shortness of breath occurred in approximately $75 \%$ of pediatric patients $[3,7,17,18]$. We found a slightly higher frequency of general symptoms such as headache, fatigue, and anosmia than in prior pediatric reports $[3,7]$. Why children have milder 


\section{A. Proportion of individuals reporting specific symptoms ( $n=1000$ unless otherwise specified)}

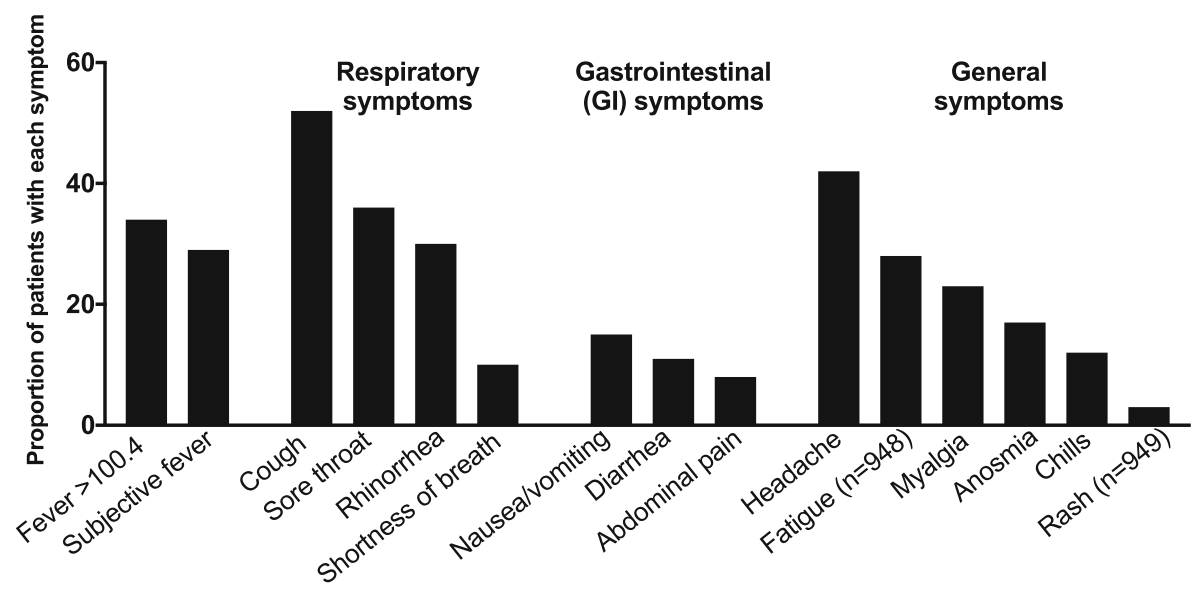

\section{B. Frequency of individual and combination symptom types}

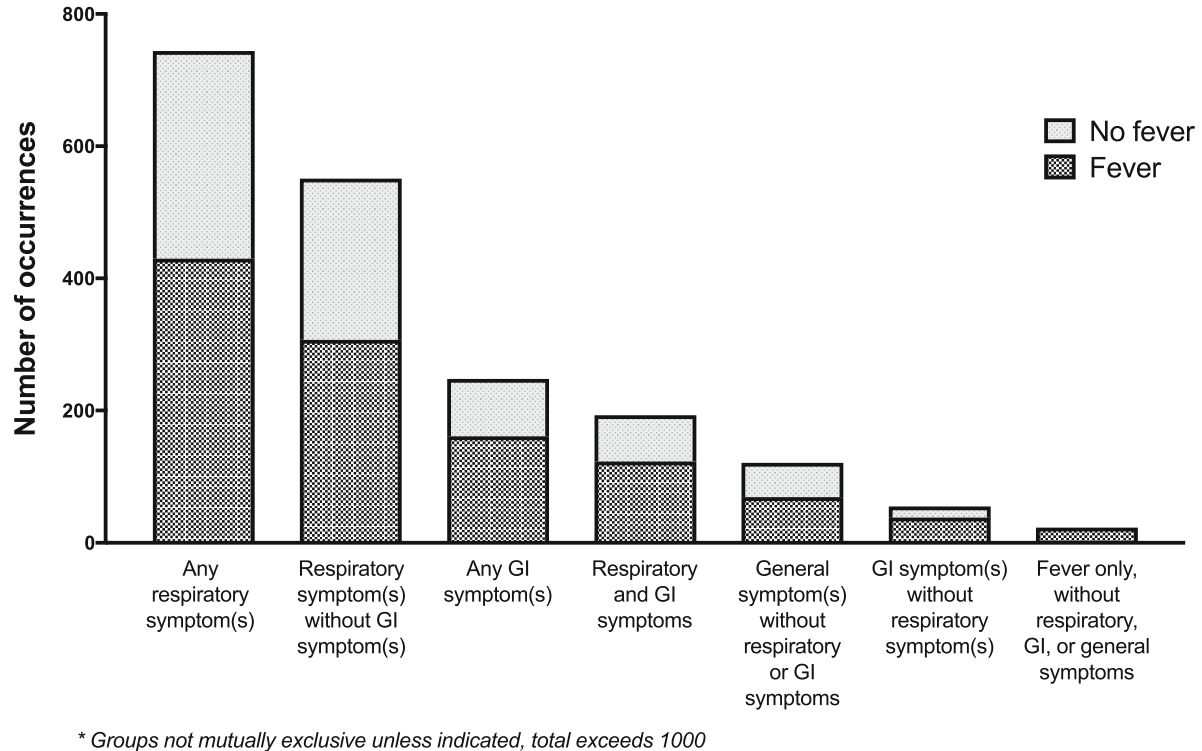

Fig. 1 A Proportion of individuals reporting specific symptoms by symptom type (fever, respiratory symptoms, gastrointestinal symptoms, general symptoms); B Frequency of occurrence of symptom types (respiratory gastrointestinal, general) alone and in combination

COVID-19 phenotypes than adults is not wellestablished, although studies have suggested that risk of developing clinical symptoms following SARS-CoV-2 infection increases with age [19]. A recent study reported high colocalization of SARS-CoV-2 in lung cells expressing TMPRSS2, in which expression increases with age, suggesting a plausible explanation for age-related differences in SARS-CoV-2 susceptibility [20]. While children may have a lower susceptibility to SARS-CoV-2 infection and severe disease, nearly 3 million U.S. children have been infected to date, suggesting that the burden of pediatric disease is substantial [21]. A recent report of children in North Carolina identified Hispanic ethnicity and having a SARS-CoV-2 infected sibling as risk factors associated with SARS-CoV-2 infection after exposure [22]. The implications of these findings on public health measures to mitigate transmission are still being unraveled. While children are considered key drivers of transmission of many respiratory viruses, early data seemed to suggested that children may not be the primary drivers of SARS-CoV-2 transmission within households and communities [23]. This recent study from North Carolina and another household study from Tennessee and Wisconsin provide increasing evidence to support the potential role for children in SARS-CoV-2 transmission [24]. However, the efficiency of transmission in the setting of mild or subclinical infection is unclear. Thus, impact of community interventions to mitigate SARS- 
Table 2 Univariate comparison of patients not hospitalized vs. hospitalized among symptomatic SARS-CoV-2 positive children and adolescents diagnosed between 3/12/2020 and 9/28/2020

\begin{tabular}{|c|c|c|c|c|}
\hline & Not hospitalized $(n=959)$ & Hospitalized $(n=41)$ & OR $(95 \% \mathrm{Cl})$ & $p$-value \\
\hline$\overline{\text { Age, mean } \pm S D \text {, median (IQR) }}$ & $12.1 \pm 6.0,14.1(7.4-17.3)$ & $10.0 \pm 7.7,12.2(0.9-17.1)$ & $0.95(0.90-1.00)$ & $0.077^{b}$ \\
\hline Male gender & $459(47.9 \%)$ & $18(43.9 \%)$ & $0.9(0.5-1.6)$ & $0.619^{a}$ \\
\hline Race & & & & $0.086^{\mathrm{a}}$ \\
\hline White & $760(79.2 \%)$ & $29(70.7 \%)$ & Reference & \\
\hline Black & $118(12.3 \%)$ & $10(24.4 \%)$ & $2.2(1.1-4.7)$ & \\
\hline Asian & $41(4.3 \%)$ & $2(4.9 \%)$ & $1.3(0.3-5.5)$ & \\
\hline Other & $40(4.2 \%)$ & $0(0.0 \%)$ & $0.0(0.0-\infty)$ & \\
\hline Hispanic & $188(19.6 \%)$ & $15(36.6 \%)$ & $2.4(1.2-4.6)$ & $0.008^{\mathrm{a}}$ \\
\hline Black or Hispanic & $304(31.7 \%)$ & $25(61.0 \%)$ & $3.4(1.8-6.4)$ & $<0.001^{\mathrm{a}}$ \\
\hline Body mass index, mean $\pm S D$, median, BMI Category & $21.9 \pm 5.5,21.0(18.0-24.4)$ & $22.5 \pm 7.7,20.9(16.1-25.6)$ & $1.02(0.96-1.08)$ & $\begin{array}{l}0.849^{b} \\
0.435^{a}\end{array}$ \\
\hline Underweight & $153(28.4 \%)$ & $12(35.3 \%)$ & $1.49(0.67-3.3)$ & \\
\hline Normal weight & $266(49.4 \%)$ & $14(41.2 \%)$ & Reference & \\
\hline Overweight & $72(13.4 \%)$ & $3(8.8 \%)$ & $0.79(0.22-2.83)$ & \\
\hline Obese & $47(8.7 \%)$ & $5(14.7 \%)$ & $2.02(0.70-5.88)$ & \\
\hline Clinical Symptoms & & & & $0.229^{a}$ \\
\hline Anosmia (loss of smell) & $162(16.9 \%)$ & $4(9.8 \%)$ & $0.5(0.2-1.5)$ & \\
\hline Shortness of breath(dyspnea) & $81(8.4 \%)$ & $17(41.5 \%)$ & $7.7(4.0-14.9)$ & $<0.001^{\mathrm{a}}$ \\
\hline Sore throat & $357(37.2 \%)$ & $4(9.8 \%)$ & $0.2(0.1-0.5)$ & $<0.001^{a}$ \\
\hline Vomiting & $12(1.3 \%)$ & $4(9.8 \%)$ & $8.5(2.6-27.7)$ & $<0.001^{\mathrm{a}}$ \\
\hline Fever $>100.4 \mathrm{~F}$ & $314(32.7 \%)$ & $23(56.1 \%)$ & $2.6(1.4-4.9)$ & $0.002^{\mathrm{a}}$ \\
\hline Headache & $420(43.8 \%)$ & $4(9.8 \%)$ & $0.2(0.05-0.39)$ & $<0.001^{\mathrm{a}}$ \\
\hline Hypoxia & 1 (0.1\%) & $11(26.8 \%)$ & $351.3(43.9-2809.2)$ & $<0.001^{a}$ \\
\hline Abdominal pain & $74(7.7 \%)$ & $8(19.5 \%)$ & $2.9(1.3-6.5)$ & $0.007^{\mathrm{a}}$ \\
\hline Nausea or vomiting & $139(14.5 \%)$ & $8(19.5 \%)$ & $1.4(0.6-3.2)$ & $0.374^{a}$ \\
\hline Pre-existing condition(s) & $150(15.6 \%)$ & $27(65.9 \%)$ & $10.4(5.3-20.3)$ & $<0.001^{\mathrm{a}}$ \\
\hline Immunocompromising condition & $4(0.4 \%)$ & $5(12.2 \%)$ & $33.2(8.5-128.7)$ & $<0.001^{\mathrm{a}}$ \\
\hline Neurologic condition & $24(2.5 \%)$ & $9(22.0 \%)$ & $11.0(4.7-25.5)$ & $<0.001^{\mathrm{a}}$ \\
\hline Cardiovascular disease & $19(2.0 \%)$ & $8(19.5 \%)$ & $12.0(4.9-29.4)$ & $<0.001^{\mathrm{a}}$ \\
\hline Chronic renal disease & $5(0.5 \%)$ & $3(7.3 \%)$ & $15.1(3.5-65.4)$ & $<0.001^{\mathrm{a}}$ \\
\hline Chronic lung disease & $69(7.2 \%)$ & $8(19.5 \%)$ & $3.1(1.4-7.0)$ & $<0.004^{a}$ \\
\hline Diabetes & $9(0.9 \%)$ & $1(2.4 \%)$ & $2.6(0.3-21.3)$ & $<0.344^{\mathrm{a}}$ \\
\hline Other chronic condition & $53(5.5 \%)$ & $11(26.8 \%)$ & $6.3(3.0-13.2)$ & $<0.001^{\mathrm{a}}$ \\
\hline
\end{tabular}

denotes a $P$ value based on a chi-square test

bdenotes a $P$ value based a Mann-Whitney $U$ test

'denotes a $P$ value based on a Fisher's exact test

CoV-2 transmission aimed at children, such as school closures, may have relatively minor impacts compared with interventions that target older populations.

Our data suggest that predictors of hospitalization following COVID-19 diagnosis differ between children and adults. In adults, increasing age, male sex, and obesity have been reported as predictors of severe disease and poor outcomes associated with COVID-19 [25-27]. In our study, COVID-19 associated hospitalization in children was associated with comorbid conditions, Black race, Hispanic ethnicity, dyspnea and vomiting, but not age, BMI, weight, or male gender. Our findings support a recent assessment of $>5000$ pediatric patients with SARS-CoV2 infection, in which an underlying medical condition and Black race were significantly associated with severe COVID-19 [28]. Our study, like many others, calls attention to the racial and ethnic disparities in SARS-CoV-2 infection rates and outcomes [22]. 


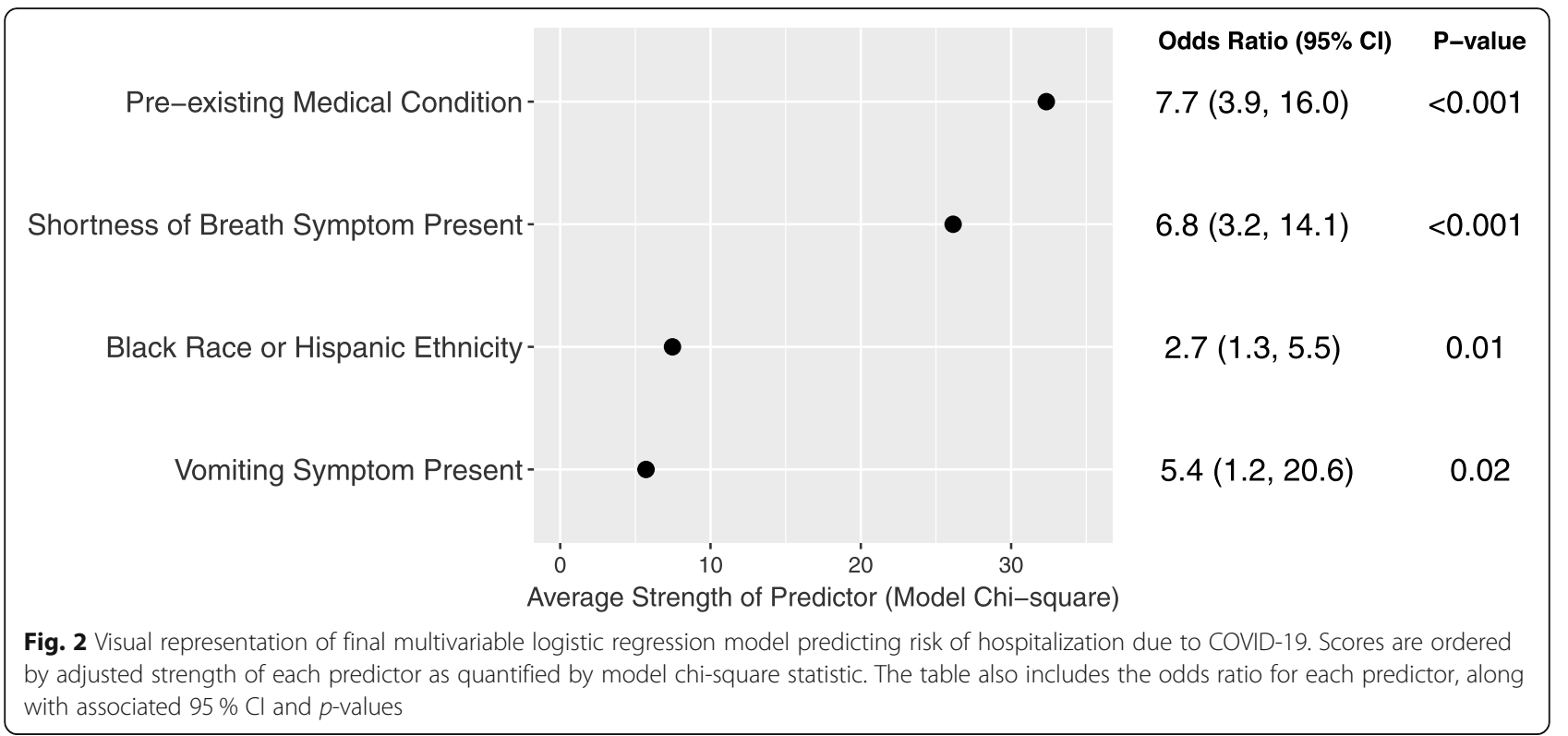

Associations between hospitalizations for COVID-19 and socioeconomic factors, social deprivation and access to healthcare warrant further study.

Our study has several strengths, including a large sample size and identification of all children with SARSCoV-2 detections in an integrated health network including diverse ambulatory and inpatient settings, enabling a comprehensive assessment of the full spectrum of pediatric infections in the community. By prospectively following these subjects, we were able to assess not only the symptoms present at diagnosis, but also to follow the duration of symptoms.

Our study is also subject to some limitations. Our cohort was limited to patients who visited one of the testing sites. We had few patients who were hospitalized and hospitalization may not be a reliable surrogate for severe COVID-19 in children, as children with preexisting conditions are more likely to be hospitalized for milder symptoms in the setting of the diagnosis of SARS-CoV-2 infection. Additionally, BMI information was unavailable in the EMR for many subjects.

Despite these limitations, we determined that while SARS-CoV-2 symptoms are generally mild and shortlived in most children, having a pre-existing medical condition is strongly associated with pediatric hospitalization following COVID-19 diagnosis. These findings can be used by clinicians and policy makers to prioritize at-risk pediatric populations for vaccination, novel therapeutics, and closer follow-up as the COVID19 pandemic continues.

\section{Abbreviations}

SARS-CoV-2: Severe acute respiratory syndrome coronavirus 2; COVID19: Coronavirus disease 2019; MIS-C: Multisystem inflammatory syndrome in children; U.S.: United States; PCR: Polymerase chain reaction;
VUMC: Vanderbilt University Medical Center; ED: Emergency department; CDC: Centers for Disease Control and Prevention; EMR: Electronic medical record; BMI: Body mass index; IQR: Interquartile range; Gl: Gastrointestinal

\section{Supplementary Information}

The online version contains supplementary material available at https://doi. org/10.1186/s12887-021-02863-1.

Additional file 1: Supplementary Table 1. Clinical features of symptomatic SARS-CoV-2 infections among 1000 pediatric patients overall and by age group. Supplementary Table 2. Clinical characteristics of hospitalizations among the first 1000 symptomatic pediatric SARS-CoV-2 infections in our network ( $n=41$ patients hospitalized). Supplementary Table 3. Predictive Model of Hospitalization. Supplementary Figure $\mathbf{1}$. Histogram presenting age distribution (years) among 1000 symptomatic SARS-CoV-2 positive children and adolescents diagnosed between 3/12/ 2020 and 9/28/2020. Supplementary Figure 2. Tree diagram of the factors in the model for hospitalization. This classification and regression tree illustrated how the risk factors are related to hospitalization. Among the 1000 children with COVID-19, 4.1\% (41) were hospitalized (1), 95.9\% were not hospitalized. The strongest predictor of hospitalization was presence of a pre-existing condition (PEC). Among the 177 patients with a PEC, $15.3 \%$ were hospitalized vs. $1.7 \%$ of those without a PEC. Among those with a PEC, the next best predictor of hospitalization was shortness of breath (SOB). The hospitalization rate was 53.5\% among those with both a PEC and SOB vs. $8.1 \%$ among those with a PEC but no SOB. Patients who are black or Hispanic were at increased risk of hospitalization among both those with and without PEC. Supplementary Figure 3. Tree diagram of 'pre-existing conditions' in the model for hospitalization, and the relative contributions of immunologic, neurologic, and renal conditions to the predictive model. Supplementary Figure 4. Association between Age, Weight, and Hospitalization. The locally weighted scatter plot smoothing lines illustrate the relationship between weight and age in the hospitalized and non-hospitalized patients. The dark bands represent the $95 \%$ confidence interval of each line. Supplementary Figure 5. Calibration curve for multivariate model predicting hospitalization. Calibration plot showing predicted probability of hospitalization vs. observed rate of hospitalization

\section{Acknowledgements}

We are grateful for the hard work and dedication of the University Medical Center clinical laboratory staff and Dr. Swathi Eyyunni. 


\section{Role of funder/sponsor}

N/A.

\section{Authors' contributions}

LH drafted the initial manuscript, carried out the initial analyses, and revised the manuscript. KG and JG designed the data collection instruments, collected data, and reviewed and revised the manuscript. KL, AS, and JS collected data and reviewed and revised the manuscript. HD and RM carried out data analysis, designed and drafted data figures, and reviewed and revised the manuscript. DB carried out data analysis, revised and reviewed the manuscript, and critically reviewed the manuscript for important intellectual content. SW conceptualized the study, reviewed and revised the manuscript, and critically reviewed the manuscript for important intellectual content. NH critically reviewed the manuscript for important intellectual content. RB conceptualized the study, supported the design of the data collection instrument, supervised the data analysis, reviewed and revised the manuscript, and critically reviewed the manuscript for important intellectual content. All authors approved the final manuscript as submitted and agree to be accountable for all aspects of the work.

\section{Funding}

Dr. Howard is supported by the National Institutes of Health under award number 1K23Al141621. This work was performed by Dr. Howard as a Young Investigator Award recipient of the IDSA Education and Research Foundation (ERF) sponsored by Pfizer.This project was conducted with no specific financial support.

\section{Availability of data and materials}

The datasets used and/or analysed during the current study are available from the corresponding author on reasonable request.

\section{Declarations}

\section{Ethics approval and consent to participate}

The study was reviewed and approved by the Vanderbilt University Medical Center Institutional Review Board as an Exempt study that did not require informed consent. All methods were performed in accordance with the Declaration of Helsinki.

\section{Consent for publication}

Not applicable.

\section{Competing interests}

The authors have no competing interests as defined by BMC, or other interests that might be perceived to influence the results and/or discussion reported in this paper.

\section{Author details}

'Department of Pediatrics, Vanderbilt University Medical Center, Nashville, TN USA. ${ }^{2}$ Department of Pathology, Microbiology, and Immunology, Vanderbilt University Medical Center, Nashville, TN, USA. ${ }^{3}$ Department of Biostatistics, Vanderbilt University Medical Center, Nashville, TN, USA. ${ }^{4}$ Medical Center North, 1161 21st Avenue South, Nashville, Tennessee, USA.

Received: 14 February 2021 Accepted: 25 August 2021

Published online: 13 September 2021

\section{References}

1. Myers LC, Parodi SM, Escobar GJ, Liu VX. Characteristics of Hospitalized Adults With COVID-19 in an Integrated Health Care System in California. JAMA. 2020;323:2195-8

2. Guan WJ, Ni ZY, Hu Y, Liang WH, Ou CQ, He JX, et al. Clinical Characteristics of Coronavirus Disease 2019 in China. N Engl J Med. 2020;382:1708-20

3. Team CC-R. Coronavirus Disease 2019 in Children - United States, February 12-April 2, 2020. MMWR Morb Mortal Wkly Rep. 2020;69(14):422-6.

4. Covid-19 National Emergency Response Center E, Case Management Team KCfDC, Prevention. Coronavirus Disease-19: The First 7,755 Cases in the Republic of Korea. Osong Public Health Res Perspect. 2020;11 (2):85-90.

5. Sun K, Chen J, Viboud C. Early epidemiological analysis of the coronavirus disease 2019 outbreak based on crowdsourced data: a population-level observational study. Lancet Digit Health. 2020;2(4):e201-e8.
6. Dong Y, Mo X, Hu Y, Qi X, Jiang F, Jiang Z, et al. Epidemiology of COVID-19 Among Children in China. Pediatrics. 2020;145(6):e20200702.

7. Otto WR, Geoghegan S, Posch LC, Bell LM, Coffin SE, Sammons JS, et al. The Epidemiology of SARS-CoV-2 in a Pediatric Healthcare Network in the United States. J Pediatric Infect Dis Soc. 2020;9:523-9.

8. Riphagen S, Gomez X, Gonzalez-Martinez C, Wilkinson N, Theocharis P. Hyperinflammatory shock in children during COVID-19 pandemic. Lancet. 2020;395:1607-8.

9. Verdoni L, Mazza A, Gervasoni A, Martelli L, Ruggeri M, Ciuffreda M, et al. An outbreak of severe Kawasaki-like disease at the Italian epicentre of the SARS-CoV-2 epidemic: an observational cohort study. Lancet. 2020;395: $1771-8$.

10. Ramcharan T, Nolan O, Lai CY, Prabhu N, Krishnamurthy R, Richter AG, et al. Paediatric Inflammatory Multisystem Syndrome: Temporally Associated with SARS-CoV-2 (PIMS-TS): Cardiac Features, Management and Short-Term Outcomes at a UK Tertiary Paediatric Hospital. Pediatr Cardiol. 2020;41:1391-401.

11. Chiotos K, Bassiri H, Behrens EM, Blatz AM, Chang J, Diorio C, et al. Multisystem Inflammatory Syndrome in Children During the Coronavirus 2019 Pandemic: A Case Series. J Pediatric Infect Dis Soc. 2020;9(3):393-8.

12. Panupattanapong S, Brooks EB. New spectrum of COVID-19 manifestations in children: Kawasaki-like syndrome and hyperinflammatory response. Cleve Clin J Med. 2020;29:1-7.

13. Dufort E, Koumans E, Chow E, Rosenthal E, Muse A, Rowlands J, et al. Multisystem Inflammatory Syndrome in Children in New York State. New England J Med. 2020;383:347-58.

14. Godfred-Cato S, Bryant B, Leung J, Oster M, Conklin L, Abrams J, et al. COVID-19-Associated Multisystem Inflammatory Syndrome in Children United States, March-July 2020. MMWR Morb Mortal Wkly Rep. 2020;69: 1074-80.

15. Wang Y, Zhu F, Wang C, Wu J, Liu J, Chen X, et al. Children Hospitalized With Severe COVID-19 in Wuhan. Pediatr Infect Dis J. 2020;39(7):e91-e4.

16. Richardson S, Hirsch JS, Narasimhan M, Crawford JM, McGinn T, Davidson KW, et al. Presenting Characteristics, Comorbidities, and Outcomes Among 5700 Patients Hospitalized With COVID-19 in the New York City Area. JAMA. 2020;323:2052-9.

17. Swann OV, Holden KA, Turtle L, Pollock L, Fairfield CJ, Drake TM, et al. Clinical characteristics of children and young people admitted to hospital with covid-19 in United Kingdom: prospective multicentre observational cohort study. BMJ. 2020;370:m3249.

18. Burke RM, Killerby ME, Newton S, Ashworth CE, Berns AL, Brennan S, et al. Symptom Profiles of a Convenience Sample of Patients with COVID-19 United States, January-April 2020. MMWR Morb Mortal Wkly Rep. 2020; 69(28):904-8.

19. Davies NG, Klepac P, Liu Y, Prem K, Jit M, group CC-W, et al. Age-dependent effects in the transmission and control of COVID-19 epidemics. Nat Med. 2020;26:1205-11.

20. Schuler BA, Habermann AC, Plosa EJ, Taylor CJ, Jetter C, Negretti NM, et al. Age-determined expression of priming protease TMPRSS2 and localization of SARS-CoV-2 in lung epithelium. J Clin Invest. 2020:131:e140766.

21. Children and COVID-19: State Data Report. A joint report from the American Academy of Pediatrics and the Children's Hospital Association 2020. https:// www.aap.org/en/pages/2019-novel-coronavirus-covid-19-infections/ children-and-covid-19-state-level-data-report/.

22. Hurst JH, Heston SM, Chambers HN, Cunningham HM, Price MJ, Suarez L, et al. SARS-CoV-2 Infections Among Children in the Biospecimens from Respiratory Virus-Exposed Kids (BRAVE Kids) Study. Clin Infect Dis. 2020;3: ciaa1693.

23. Posfay-Barbe KM, Wagner N, Gauthey M, Moussaoui D, Loevy N, Diana A, et al. COVID-19 in Children and the Dynamics of Infection in Families. Pediatrics. 2020;146:e20201576.

24. Grijalva CG, Rolfes MA, Zhu Y, McLean $H Q$, Hanson KE, Belongia EA, et al. Transmission of SARS-COV-2 Infections in Households - Tennessee and Wisconsin, April-September 2020. MMWR Morb Mortal Wkly Rep. 2020; 69(44): :1631-4

25. Yang X, Yu Y, Xu J, Shu H, Xia J, Liu H, et al. Clinical course and outcomes of critically ill patients with SARS-CoV-2 pneumonia in Wuhan, China: a singlecentered, retrospective, observational study. Lancet Respir Med. 2020;8:475481.

26. Zhou F, Yu T, Du R, Fan G, Liu Y, Liu Z, et al. Clinical course and risk factors for mortality of adult inpatients with COVID-19 in Wuhan, China: a retrospective cohort study. Lancet. 2020;395(10229):1054-62. 
27. Docherty $A B$, Harrison EM, Green CA, Hardwick HE, Pius R, Norman $L$, et al. Features of 20133 UK patients in hospital with covid-19 using the ISARIC WHO Clinical Characterisation Protocol: prospective observational cohort study. BMJ. 2020;369:m1985.

28. Bailey LC, Razzaghi H, Burrows EK, Bunnell HT, Camacho PEF, Christakis DA, et al. Assessment of 135794 Pediatric Patients Tested for Severe Acute Respiratory Syndrome Coronavirus 2 Across the United States. JAMA Pediatr. 2020;175:176-84

\section{Publisher's Note}

Springer Nature remains neutral with regard to jurisdictional claims in published maps and institutional affiliations.

Ready to submit your research? Choose BMC and benefit from:

- fast, convenient online submission

- thorough peer review by experienced researchers in your field

- rapid publication on acceptance

- support for research data, including large and complex data types

- gold Open Access which fosters wider collaboration and increased citations

- maximum visibility for your research: over $100 \mathrm{M}$ website views per year

At $B M C$, research is always in progress.

Learn more biomedcentral.com/submissions 